\title{
SMART CABIN TEMPERATURE AND GAS CONTROLLING SYSTEM FOR CAR
}

\author{
${ }^{1}$ Vinukumar Luckose*, ${ }^{2}$ Arvin Rau A/L Gunarayu, ${ }^{3}$ Sajitha Smiley Masillamony, ${ }^{1}$ Noor \\ Farhana Halil Binti Abdul Razak
}
${ }^{1}$ Faculty of Engineering, Built Environment and Information Technology, SEGi University, 47810 Petaling Jaya, Selangor, Malaysia.
${ }^{2}$ SOSM Testing department, ON Semiconductor, Lorong Senawang 2/4, Kawasan Perusahaan Senawang, 70450 Seremban, Negeri Sembilan.
${ }^{3}$ School of Engineering and Technology, Linton University College, Bandar Universiti Teknologi Legenda (BUTL), 71700 Mantin, Negeri Sembilan, Malaysia.

* Corresponding Author: vinukumarluckose@segi.edu.my TEL: (+60)-183128750

\begin{abstract}
Car owners especially in these days, are facing more problems due to the high temperatures when parking the car under burning sun due to the air temperature rise inside the car and production of harmful gases. In this paper, the design and development of a smart car air cooling system with the help of a temperature sensor and carbon monoxide sensor has described. The system was developed with microcontroller, Wi-Fi module, fan, sensors and other control circuitry to manage the system to operate manually and automatically. With the help of mobile application, the owner is able to receive the information regarding the level of temperature and the percentage of gas inside the car. The system is able to begin working when the temperature reaches $30^{\circ} \mathrm{C}$ and stop automatically when the temperature comes below $25^{\circ} \mathrm{C}$. The temperature level inside and outside of the car was measured and the highest temperature inside the car cabin was observed to be $61^{\circ} \mathrm{C}$. The principle of operation and theoretical analysis was provided. The experimental results were provided with the level of temperature and percentage of gas emissions inside the car under sunlight.
\end{abstract}

Keywords: Wi-Fi Module; Microcontroller; Car Cooling System; Temperature Sensor; Carbon Monoxide Sensor

\section{Introduction}

Nowadays, the world faces serious global warming and environmental changes due to the high value of temperatures. This temperature affects the vehicles specially when it is parked under 
the sunlight for long hours. To date, most of the people prefer to use car for transportation compared to public transport. With the increase in cars, parking has become a problem, especially in the shopping area. Those who are unable to park indoors or who prefer a lower parking fee will have to park their cars in the open space (Shireesha, Karthik \& Mohan, 2015) Leaving the car parked outdoors under direct sunlight can increase the cabin temperature by up to $60^{\circ} \mathrm{C}$ (Saidur, Masjuki, \& Hasanuzzaman, 2009). The temperature inside the vehicle cabin rises to $80^{\circ} \mathrm{C}$ when parked in direct sunlight (Al-Kayiem, Sidik, \& Munusammy, 2010). In the first 10 minutes, the driver feels uncomfortable because of the hot temperature inside the car (Mezrhab \& Bouzidi, 2006). A study by Stanford University School of Medicine has found that on a relatively cool day, the temperature inside a parked car can quickly rise to dangerous levels (McLaren, Null, \& Quinn, 2005).

There have been at least 468 infant deaths caused by thermal heat in parked cars since 1998, and alot of drivers had reported of an uncomfortable feeling in their cars due to the heat (Saidur, Masjuki, \& Hasanuzzaman, 2009). According to an Australian study for forensic, the temperature of a parked vehicle is normally $20^{\circ} \mathrm{C}$ higher than the outside temperature during sunny days. Furthermore, children or pets left in a parked car for more than 30 minutes may suffer heat exhaustion and death (Ahmad \& Turi, 2018). In another report published by the National Highway Traffic Safety Administration (2002), it mentioned that a car window traps heat in a confined space, and approximately 25 kids per year die in hot vehicles after being left unattended.

The temperature rises immediately when the vehicle is exposed directly to solar radiation. The high cabin temperature may threaten children's and animals when they are unattended in the vehicle. In the USA, heat stroke causes a death rate of 37 children's every year. Furthermore, the high cabin temperature may damage the drugs in the ambulance and the veterinary vehicle (Johannes et al, 2017). The internal temperature of the car depends upon the outside temperature, car model and the location with high temperature density. The high temperature rise is caused by greenhouse effect which is associated with the imbalance in the heat radiation and less ventilation (Roberts \& Roberts, 1976). According to a consumer report by Emily (2021), the cabin temperature inside the car can reach to a dangerous level within an hour during the day with mild temperatures. The consumer report also conducted many temperature tests inside the closed vehicles using a precision instrument. One of the day in June, the average temperature measured was $41^{\circ} \mathrm{C}$ at outside for the first 1 hour of testing and the temperature inside the parked car reached more than $65^{\circ} \mathrm{C}$. Another test was conducted in different day as 
shown in Figure 1 in the month of July with a lighter coloured and dark coloured sedan car. With the average value of $48^{\circ} \mathrm{C}$ temperature at the outside for a one 1 hour of the test period, the inside of the lighter coloured sedan reached $64{ }^{\circ} \mathrm{C}$ temperature and the dark coloured sedan reached $68^{\circ} \mathrm{C}$ temperature. The temperature test as shown in Figure 2, was conducted by Catherine et al, 2005 in vehicles under closed window and cracked window condition. From the observation, there is a difference of $10^{\circ} \mathrm{C}$ temperature rise between the above said condition. But the cabin temperature is reached to the same value when the time approaches to 50-55 minutes. This reflects that even the windows with cracked condition after a few minutes the cabin temperature rises to the same temperature level with the vehicle with closed window.

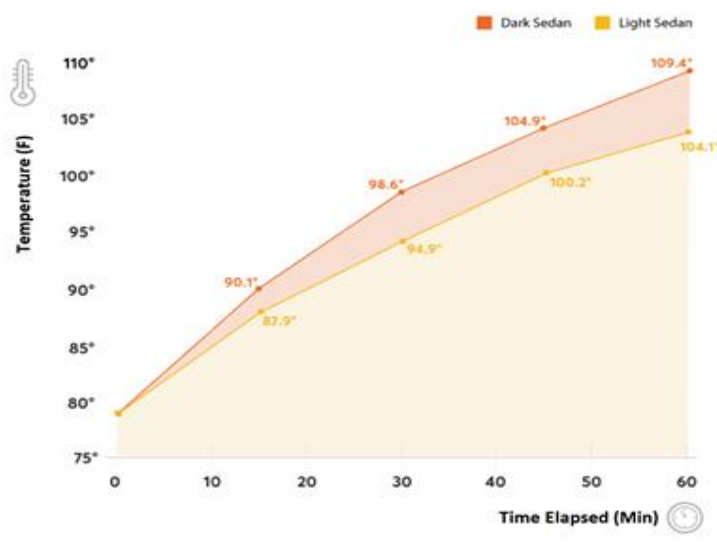

Figure 1: Vehicle temperature rise in 1 hour (Emily, 2021)

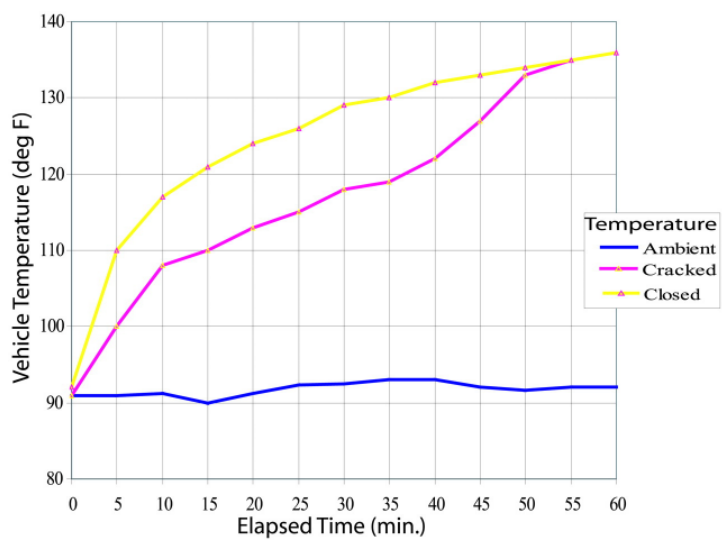

Figure 2: Interior vehicle temperature under closed and cracked car windows (Catherine et al, 2005)

Most vehicles are manufactured and equipped with efficient heating, ventilation and air conditioning system. However, when the vehicles parked under the hot sun, the temperature inside the car is usually higher than outside. This high temperature increases the production of harmful gas inside the car due to the presence of dashboards, leather seat and plastic accessories. Sometimes, people need to stay outside of the car for few minutes after turning on the car engine and the air conditioning system to mitigate the effect high temperature and the harmful gasses (Baltha \& Baltha, 2017). According to Yang et al, (2019) various harmful gasses that could be produced inside the vehicles includes carbon monoxide concentration, formaldehyde concentration, benzene, styrene, nitrogen oxide and PM 2.5. These gases may stay in the car and when the peoples are exposed to these harmful gases can affect their health. Peoples who inhale these gases at high levels may develop the health related symptoms they 
are; irregular heartbeat, unconsciousness and tiredness even may lead to death (Shanmugaraja et al, 2019).

Various system has been developed to reduce the effect of high cabin temperature and the harmful gases. A new ventilation system has been designed by Shanmugaraja et al, (2019) constructed by a thermoelectric cooler, temperature sensors and other electronic control circuitry. The designed system controlled the temperature rise automatically under the situation even when the car engine is off. The thermoelectric cooler in the car controlled by a separate control circuit, and when the temperature reaches to $35^{\circ} \mathrm{C}$ the thermoelectric cooler turned on and the thermoelectric cooler off when the cabin temperature falls to $28^{\circ} \mathrm{C}$. The cooling system proposed by Basar et al (2013) is able to control and maintain the temperature inside the car in the range of 25 to 30 when parked under very hot condition.

The experimental study was conducted by Sudhir \& Jalal (2015) in a parked car with the cabin ventilation system controlled by solar energy. The cabin temperature has tested in two different conditions. One is with the existing air conditioning system in the car, another with the developed ventilation system of solar energy. The experimental results show that with the developed ventilation system the cabin temperature reached a comfortable level than the existing air conditioning system in the car. The Controller Area Network (CAN) based module was developed by Prasad, Kumar \& Asadi (2016) to cut the high cabin temperature in the vehicle. A group of sensors and two microcontrollers used to process the data efficiently and reliably to make sure the safe ventilation condition. The intelligent system designed with modular solar energy Ciocanea \& Buretea (2014) aims to remove the cabin temperature from the parked car. There are two pairs of fans used, one placed under the back seat and another on the car roof. The cabin temperature and humidity has measured under the solar radiation (600$800 \mathrm{~W} / \mathrm{m}^{2}$ ) with no ventilation and the collected data used to design the fans.

The aim of this paper is to design a smart temperature and gas monitoring system to reduce the cabin temperature in a car. The system able to detect the cabin temperature and the amount of carbon monoxide gas inside the car automatically. The ventilation system was developed with microcontroller, Wi-Fi module, fan, temperature sensor and carbon monoxide sensor. The owner of the car is able to monitor the cabin temperature and the percentage of gas through the smart phone application. The fan can also be controlled by owner through setting the limits in the smart phone. When the cabin temperature increased to $30^{\circ} \mathrm{C}$ the ventilation system starts automatically and release the hot air from the car. Once the cabin temperature reaches to $25^{\circ} \mathrm{C}$ 
the ventilation system stops working. The carbon monoxide sensor monitors the percentage level of gas inside the car and the fan start run when the gas level reached to $20 \%$.

\section{Design Methodology}

The general block diagram of the overall system design is shown in Figure 3. The main components used in this design are; power supply, ATmega 328 microcontroller, fan, Wi-Fi module, temperature and carbon monoxide sensor. The temperature sensor and carbon monoxide sensor used to detect the level of hot air and carbon monoxide gas inside the car cabin. The sensed data will be processed by the ATmega328 microcontroller for the further process. The Wi-Fi module is used to communicate between the owner mobile and the microcontroller. Furthermore, it will receive the instruction from the owner's mobile and sends it to the microcontroller to fulfil the command. The fan motor will run or stop with the commands received from the microcontroller based the cabin temperature level and the gas inside the car. The car owner can manually turn on the ventilation system in the car with the help of mobile phone 5 or 10 minutes before using the car. This will make more comfortable to the car owner to keep the cabin temperature in the range of $20-22{ }^{\circ} \mathrm{C}$. Moreover, this will avoid the system to run many times automatically when the car parked in the sunlight for long hours.

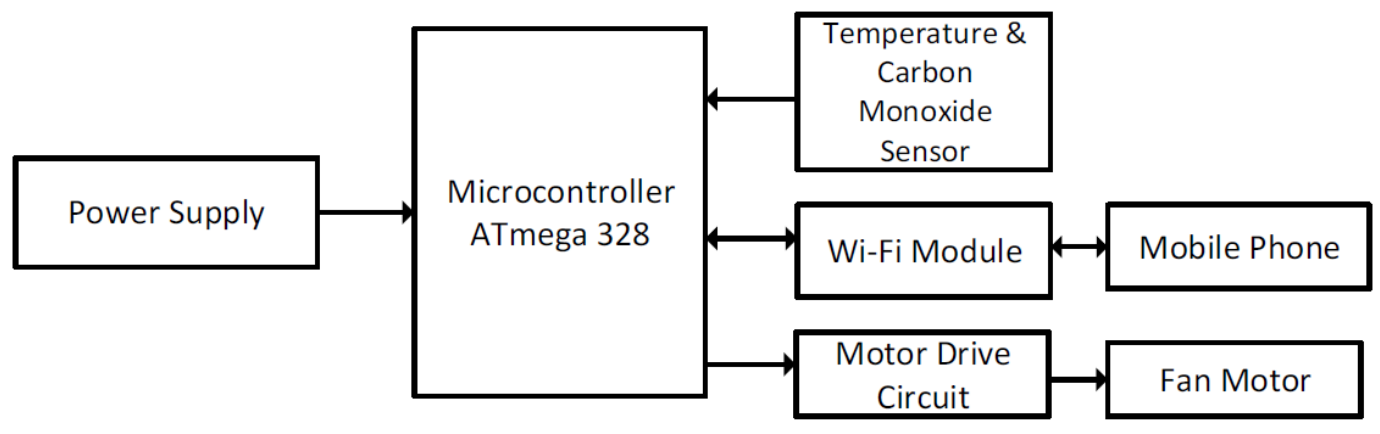

Figure 3: Block diagram of the system

Figure 4 illustrates the flow chart of the designed system. The overall process of the system will start with the turning $\mathrm{ON}$ the temperature and carbon monoxide sensor. If the temperature and the carbon monoxide gas was higher, the microcontroller will send command to the motor driver to turn ON the fan. So, the fan releases the hot air and carbon monoxide gas from the 
car. Meanwhile, Wi-Fi module will send a notification to owner mobile about the cabin temperature and the percentage of gas inside the car. If the temperature and the gas inside the car less than the value programmed into the Microcontroller, the system does not show any action.

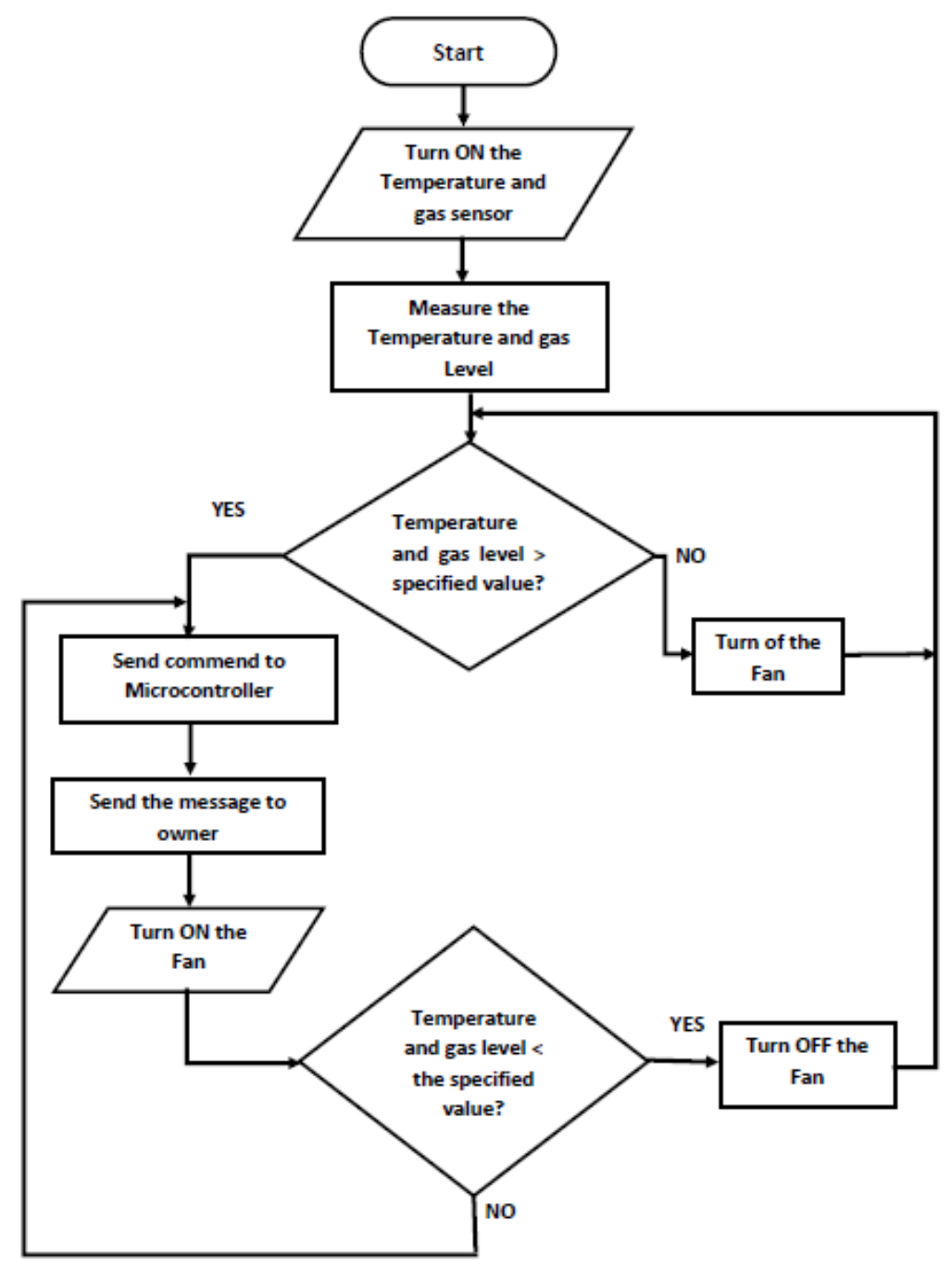

Figure 4: Design Flow chart

The overall circuit design of the system consists of temperature sensor, carbon monoxide sensor and Wi-Fi modules which have been interfaced with the microcontroller board. The WiFi module transmitter as shown in Figure 5 is connected with receiver terminal of the microcontroller. Temperature and carbon monoxide sensor acting as a receiver of the module which is connected with the microcontroller. These are the key elements or the components which used in the prototype design. The $\mathrm{Wi}-\mathrm{Fi}$ module is able to communicate between the 
system and the mobile. The system sends the commend to the DC motor fan to remove the high cabin temperature and the gas inside the car.

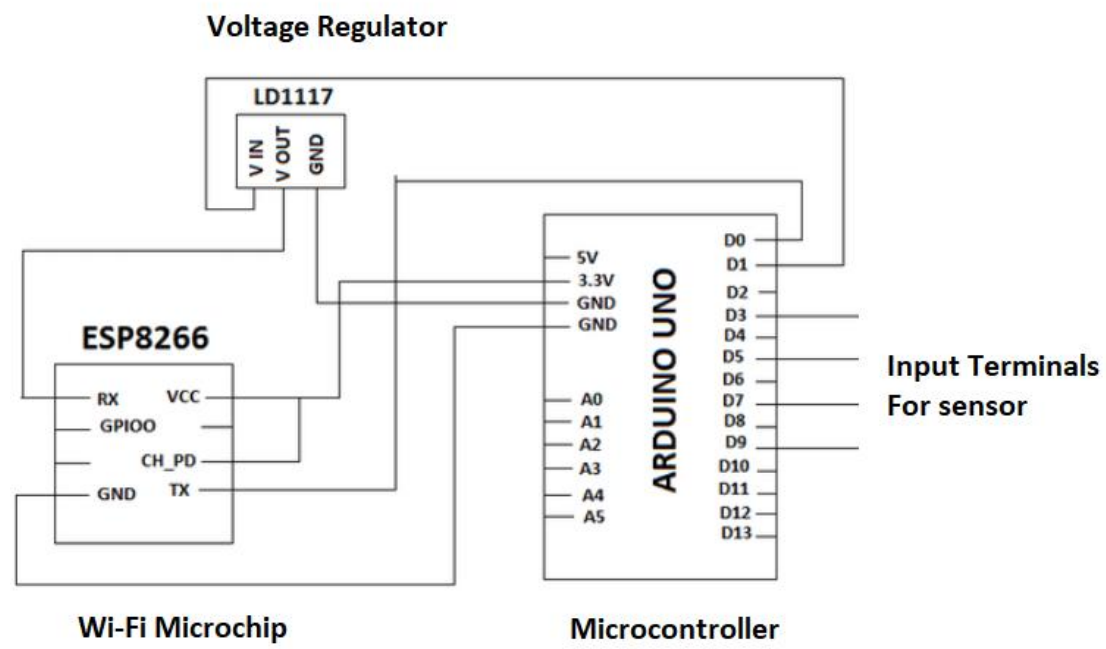

Figure 5: Circuit implementation with Microcontroller and Wi-Fi Module

\section{Results and discussion}

An experiment has conducted in a day from 8 AM to $5 \mathrm{PM}$ under hot sun in the open car parking to measure the temperature and gas level inside the car. Initially, the temperature has measured inside and outside of the car without the proposed system. Table 1 below shows the temperature data obtained at the outside and inside of the car. From the table it is observed that the temperature at the outside of the car increases from $24^{\circ} \mathrm{C}$ to $41^{\circ} \mathrm{C}$ from $8 \mathrm{AM}$ to $3 \mathrm{PM}$. But the temperature level decreases after $3 \mathrm{PM}$ from $41^{\circ} \mathrm{C}$ to $38^{\circ} \mathrm{C}$.

Table 1. Temperature at inside and outside of the car without the proposed system

\begin{tabular}{|c|c|c|c|c|c|c|c|c|c|c|}
\hline Time & $\mathbf{8}$ & $\mathbf{9}$ & $\mathbf{1 0}$ & $\mathbf{1 1}$ & $\mathbf{1 2}$ & $\mathbf{1}$ & $\mathbf{2}$ & $\mathbf{3}$ & $\mathbf{4}$ & $\mathbf{5}$ \\
\hline $\begin{array}{c}\text { TM } \\
\begin{array}{c}\text { Temperature } \\
\text { in }{ }^{\circ} \text { C } \\
\text { (Outside the } \\
\text { car) }\end{array}\end{array}$ & 24 & 27 & 28 & 34 & 38 & 40 & 41 & 41 & 40 & PM \\
\hline $\begin{array}{c}\text { Temperature } \\
\text { in }{ }^{\circ} \mathbf{C} \text { (Inside } \\
\text { the car) }\end{array}$ & 23 & 26 & 36 & 43 & 52 & 58 & 61 & 61 & 57 & PM \\
\hline
\end{tabular}

While increasing the outside temperature, the internal car temperature also increases. From the graph as in Figure 6 the temperature level in the morning at $8 \mathrm{AM}$ to $9 \mathrm{AM}$ is almost similar at inside and outside of the car. However, the difference in the level of temperature increases 
at inside of the car compared to outside due to the closed space. The highest temperature recorded from 2 to $3 \mathrm{PM}$ and the difference in temperature is $20^{\circ} \mathrm{C}$. From the graph it is identified that the temperature inside the car depends upon the outside temperature.

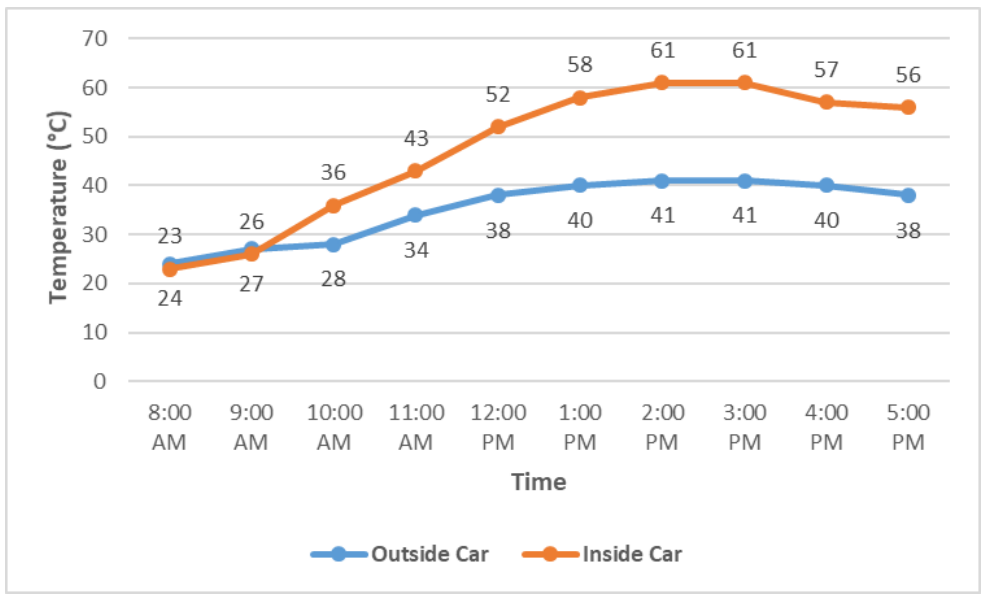

Figure 6: Temperature in ${ }^{\circ} \mathrm{C}$ (Outside and inside of car) versus Time

Secondly, the temperature and gas level inside the car had been measured without the proposed system. When the temperature inside the car increases, the carbon monoxide gas level at the inside of the car also increases. The gas level at the inside of the car has measured using the carbon monoxide sensor, and the corresponding temperature values presented in Table 2 . The gas level in the car is lesser in the morning and gradually increases to $33 \%$ in the afternoon. The level of gas inside the car depends upon the internal temperature of the car. The gas level in the car dropped to $25 \%$ in the evening around 5 PM. As discussed in the literature section, the gas level rises when the temperature in the car increases. The rise in gas level mainly because of the existence of plastic and leather materials found in the car.

Table 2. Temperature and gas level in the car without the proposed system

\begin{tabular}{|c|l|l|l|l|l|l|l|l|l|l|}
\hline Time & $\mathbf{8}$ & $\mathbf{9}$ & $\mathbf{1 0}$ & $\mathbf{1 1}$ & $\mathbf{1 2}$ & $\mathbf{1}$ & $\mathbf{2}$ & $\mathbf{3}$ & $\mathbf{4}$ & $\mathbf{5}$ \\
$\mathbf{A M}$ & $\mathbf{A M}$ & $\mathbf{A M}$ & $\mathbf{A M}$ & $\mathbf{P M}$ & $\mathbf{P M}$ & $\mathbf{P M}$ & $\mathbf{P M}$ & $\mathbf{P M}$ & $\mathbf{P M}$ \\
\hline $\begin{array}{c}\text { Temperature } \\
\text { in } \begin{array}{c}{ }^{\circ} \mathbf{C} \text { (Inside } \\
\text { the car) }\end{array}\end{array}$ & 23 & 26 & 36 & 43 & 52 & 58 & 61 & 61 & 57 & 56 \\
\hline $\begin{array}{c}\text { Gas level } \\
(\boldsymbol{\%})\end{array}$ & 10 & 13 & 14 & 17 & 25 & 29 & 32 & 33 & 29 & 25 \\
\hline
\end{tabular}

Finally, the testing has conducted with the help of the proposed system. For the testing purpose the system was located at the car rear seat. The temperature and gas level sensor able to monitor the internal temperature and gas level when the system is turned on. When the temperature in 
the car reached $30{ }^{\circ} \mathrm{C}$, the microcontroller will send the command to run the fan motor. Meanwhile, the car owner will receive the current status of temperature and gas level through the mobile phone. The microcontroller will enable the motor when the temperature is higher than $30^{\circ} \mathrm{C}$ or the gas level more than $20 \%$. However, the temperature in the car always reached to its maximum value before the gas level reached to its maximum. Table $\mathbf{3}$ shows the various temperature and gas level readings obtained from the proposed system. The temperature and gas level values are recorded from 8 AM to 9:45 AM.

Table 3. Outside temperature, inside temperature and gas level in the car with proposed system

\begin{tabular}{|c|c|c|c|c|c|c|c|}
\hline Time & $\mathbf{8}$ & $\mathbf{8 : 3 0}$ & $\mathbf{9}$ & $\mathbf{9 : 3 0}$ & $\mathbf{9 : 3 5}$ & $\mathbf{9 : 4 0}$ & $\mathbf{9 : 4 5}$ \\
$\mathbf{A M}$ & AM & AM & AM & AM & AM & AM \\
\hline $\begin{array}{c}\text { Temperature } \\
{ }^{\circ} \mathbf{C} \text { (Inside the } \\
\text { car) }\end{array}$ & 23 & 24 & 26 & 30 & 29 & 25 & 24 \\
\hline $\begin{array}{c}\text { Gas level (\%) } \\
\text { Temperature } \\
\begin{array}{c}\text { Tem (Outside the } \\
\text { car) }\end{array}\end{array}$ & 10 & 13 & 14 & 17 & 19 & 18 & 17 \\
\hline
\end{tabular}

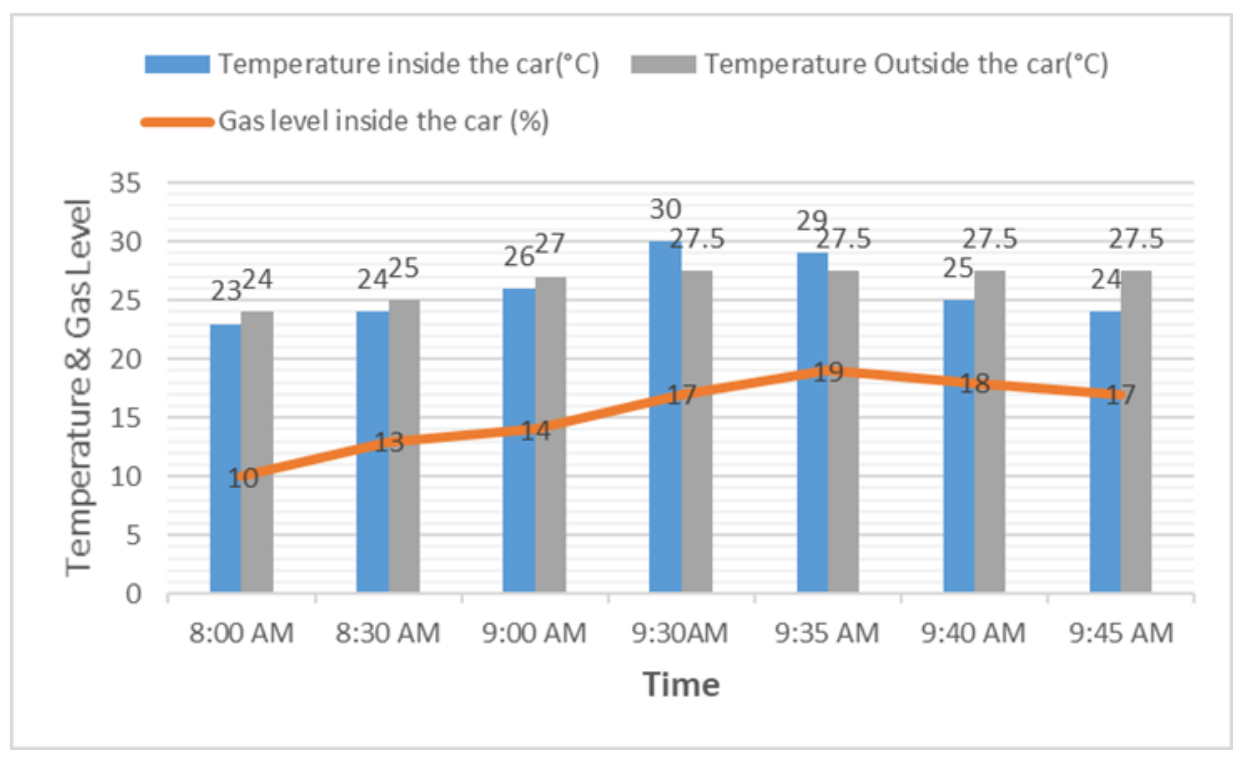

Figure 7: Temperature and gas level with proposed system

The difference in the temperature inside, outside and gas level has recorded in the graph as shown in Figure 7. From the graph, the gas level in the car rises linearly with the temperature. As soon as the temperature reaches $30^{\circ} \mathrm{C}$ the microcontroller sends commands to turn $\mathrm{ON}$ the 
fan also to the owner mobile. At 9:30 AM, the temperature at inside the car reached to $30^{\circ} \mathrm{C}$ gas level to $17 \%$. Therefore, the fan start run and the temperature inside the car decreases slowly due to the air from the fan. When the time has reached to 9:35 AM, the temperature and the gas value in the car has reduced to $29^{\circ} \mathrm{C}$ and $19 \%$ respectively. The fan continues to run until the temperature inside the car reaches to its normal value.

\section{Conclusion}

The smart cabin temperature and gas monitoring system has successfully designed and implemented. The designed smart system is developed by using microcontroller, Wi-Fi module, fan motor, temperature, and carbon monoxide sensor. The system able to turn on the fan motor when the cabin temperature reached at $30^{\circ} \mathrm{C}$. The $\mathrm{Wi}-\mathrm{Fi}$ module communicate between the car owner and the microcontroller to monitor the temperature level and gas level inside the car. The temperature level at outside and inside of the car have been measured and tabulated. The percentage level of gas inside the car under hot sun was monitored. The level of temperature and gas inside the car was higher during the afternoon. The highest temperature inside the car was measured from 2 to $3 \mathrm{PM}$ was $61^{\circ} \mathrm{C}$. The car owner able to monitor the temperature and gas level using the smart phone. The overall results show that the designed system able to maintain the temperature approaching to the room temperature value.

\section{Acknowledgement}

The authors would like to thank the Faculty of Engineering, Built Environment and Information Technology (FoEBEIT), SEGi University for supporting this research work.

\section{References}

Al-Kayiem, H. H., Sidik, M. F. B. M. \& Munusammy, Y. R. (2010). Study on the Thermal Accumulation and Distribution Inside a Parked Car Cabin. American Journal of Applied Sciences, 7(6), 784-789. https://doi.org/10.3844/ajassp.2010.784.789

Ahmad, M., \& Turi, J. A. (2018). Study of air temperature propagation of parked car. International Journal of Scientific \& Engineering. Research, 9(3), 1503-1513.

Baltha, M.K., and Baltha,S. (2017). Heat Reduction in Car Cabin by Using Nonconventional Source of Energy. International Journal of Engineering Science Invention, 6(12), 48-54.

Basar, M. F., Musa, M., Faizal, M. Y., \& Razik, N. H. A. (2013). Alternative way in reducing car cabin temperature using portable car cooling system (Car-Cool). International Journal of Innovative Technology and Exploring Engineering, 3(3), 140-143. 
Ciocanea, A., \& Buretea, D. L. (2014). Cabin heat removal from parked cars. Hidraulica, (3), 52.

Emily, A. (2021). Hot car fatalities are a year-round threat to children and pets. Retrieved 19 September 2021, from https://bit.ly/3F6Nbw7

Horak, J., Schmerold, I., Wimmer, K., \& Schauberger, G. (2017). Cabin air temperature of parked vehicles in summer conditions: life-threatening environment for children and pets calculated by a dynamic model. Theoretical and applied climatology, 130(1), 107-118.

McLaren, C., Null, J., \& Quinn, J. (2005). Heat stress from enclosed vehicles: moderate ambient temperatures cause significant temperature rise in enclosed vehicles. Pediatrics, 116(1), e109-e112

Mezrhab, A., \& Bouzidi, M. (2006). Computation of thermal comfort inside a passenger car compartment. Applied Thermal Engineering, 26(14-15), 1697-1704.

Prasad, M. V. V., Kumar, K. R., \& Asadi, S. S. (2016). A Self-Regulated Module for Vehicle Interior Ventilation System. Indian Journal of Science and Technology, 9(18).

Roberts, K. B., \& Roberts, E. C. (1976). The automobile and heat stress. Pediatrics, 58(1), 101104.

Saidur, R., Masjuki, H. H., \& Hasanuzzaman, M. (2009). Perfromance of an improved solar car ventilator. International Journal of Mechanical and Materials Engineering, 4(1), 2434.

Shanmugaraja, M., Jeipraveen, R., Ashith raj, R., \& Brian joe, M. (2019). Smart way to reduce car cabin temperature by using thermoelectric cooler. International Research Journal of Engineering And Technology (IRJET), 6(3), 8014-8019.

Shireesha, Y, Karthik, S., and Mohan, S. (2015). Comparison of Different Car Cooling Systems with Portable Car Cooling System. Journal of Mechanical and Civil Engineering 12(2), $50-57$.

Sudhir, C.V., \& Al Dhali, J. M. (2015). Effect of solar ventilation on air conditioning system performance of the car parked under sun light. ARPN Journal of Engineering and Applied Sciences, 10(22), 10618-10626.

Yang, F., Yan, P., Qi, Y., Gu, Y. F., \& Fei, G. (2020). Design of Detecting Harmful Gas Inside the Vehicle and Voice Alarm System and Concentration Prediction. Procedia Computer Science, 166, 200-205. 